\section{Shell Thickness Classifications for 46 Pecan Cultivars Grown in the Southeastern United States}

\author{
William D. Goff and Leslie R. Brasher \\ Department of Horticulture, Auburn University, AL 36849
}

\author{
Mark S. West \\ Department of Research Data Analysis, Auburn University, AL 36849
}

Additional index words. Calya illinoensis, morphology, nut crops, processing, marketing

Shell thickness in pecan [Carya illinoensis (Wangenh.) C. Koch] is an important consideration because consumers often prefer thin-shelled nuts that are easy to crack. The term "papershell," which is not precisely defined but is used in advertising to describe thin-shelled cultivars like 'Schley', appeals to this consumer preference. In commercial harvesting, thin-shelled nuts more easily are unintentionally cracked by mechanical harvesting and handling equipment than thickershelled nuts (Reid and Heaton, 1977). Shell thickness also may affect preference of pests, particularly birds, for pecan cultivars.

Kays and Payne (1982) measured shell thickness of 14 pecan cultivars and two unnamed selections. Forbus et al. (1983) examined shell thickness of 21 pecan genotypes and found shell thickness to be an important physical property influencing shelling efficiency. Our report expands the available information quantifying shell thickness of common pecan cultivars, groups cultivars into shell thickness categories, and offers suggestions on measuring shell thickness.

Pecans from 46 cultivars were sampled over several years from various orchards and experimental plantings in Alabama and Georgia. We drew a random sample of 10 nuts for each cultivar and cut each pecan longitudinally in the plane of the middle septum. Six measurements were made in that plane, or slightly distant from it if there were obvious irregularities near the juncture of the middle septum-and shell. The measurements were at $25 \%, 50 \%$, and $75 \%$ of the distance along the shell circumference from the base of the nut to the apex and were made using a microscope and ocular scale. Means of these

Received for publication 4 Feb. 1991. Alabama Agricultural Experiment Station Journal Series no. 11-912882P. The cost of publishing this paper was defrayed in part by the payment of page charges. Under postal regulations, this paper therefore must be hereby marked advertisement solely to indicate this fact. six measurements were calculated as a composite measure of shell thickness. We then further examined the data statistically by cluster analysis using average linking (Johnson and Wicheren, 1982) to determine if measuring could be simplified by selecting fewer locations. The locations with least variation and that best represented overall shell thickness were those sites $25 \%$ of the distance along the shell circumference from the base to the apex (Fig. 1). We suggest that shell thickness measurements be made at these locations. Simply clip the lower $25 \%$ of the nut off with a York Nut Sheller (Texan Nut Sheller, San Angelo, Texas) and then measure with calipers. If there are obvious thickness abnormalities at the middle septum, as we commonly observed, measure slightly away from it at a location appearing to represent prevailing shell thickness.

The range in shell thickness ranged from $0.39 \mathrm{~mm}$ for 'Hastings' to $1.26 \mathrm{~mm}$ for 'Rome' (Table 1). This range was divided into three equally spaced divisions, resulting in the three groupings (Table 1). We suggest the terms "thin," "moderate," and "thick" be used to better define shell thickness, and that use of the term "papershell" be reserved for cultivars in the "thin" category, i.e., those with shell thickness $<0.68 \mathrm{~mm}$.

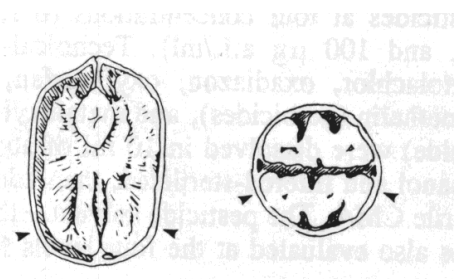

Fig. 1. Location of measurements selected to be representative of average shell thickness. Measurements are near the plane of the middle septum and are $25 \%$ of the distance along the shell circumference from the base to the apex.
Table 1. Mean shell thickness of 46 pecan cultivars and suggested shell thickness classifications.

\begin{tabular}{|c|c|c|c|}
\hline $\begin{array}{l}\text { Rank } \\
(1=\text { thickest })\end{array}$ & Cultivar & $\begin{array}{c}\text { Shell } \\
\text { thickness } \\
(\mathrm{mm})\end{array}$ & $\begin{array}{l}\text { Range } \\
(\mathrm{mm})\end{array}$ \\
\hline \multicolumn{4}{|c|}{ Thick $(>0.97 \mathrm{~mm})^{\mathrm{y}}$} \\
\hline 1 & Rome & $1.26 \pm 0.14$ & $1.03-1.54$ \\
\hline 2 & Surprize & $1.04 \pm 0.17$ & $0.79-1.24$ \\
\hline 3 & Gloria Grande & $1.01 \pm 0.10$ & $0.83-1.17$ \\
\hline 4 & Success & $1.00 \pm 0.13$ & $0.79-1.15$ \\
\hline 5 & Jackson & $0.99 \pm 0.11$ & $0.82-1.17$ \\
\hline 6 & Moneymaker & $0.98 \pm 0.22$ & $0.54-1.38$ \\
\hline \multicolumn{4}{|c|}{ Moderate (0.68 to $0.97 \mathrm{~mm})$} \\
\hline 7 & Jubilee & $0.92 \pm 0.11$ & $0.79-1.13$ \\
\hline 8 & Pabst & $0.89 \pm 0.11$ & $0.72-1.09$ \\
\hline 9 & Van Deman & $0.87 \pm 0.12$ & $0.68-1.06$ \\
\hline 10 & Pioneer & $0.85 \pm 0.16$ & $0.64-1.03$ \\
\hline 11 & Desirable & $0.84 \pm 0.11$ & $0.67-1.03$ \\
\hline 12 & Elliott & $0.83 \pm 0.13$ & $0.67-1.03$ \\
\hline 13 & Nelson & $0.83 \pm 0.16$ & $0.60-1.09$ \\
\hline 14 & Candy & $0.83 \pm 0.07$ & $0.74-0.95$ \\
\hline 15 & Choctaw & $0.79 \pm 0.27$ & $0.51-1.39$ \\
\hline 16 & Kiowa & $0.79 \pm 0.09$ & $0.64-0.94$ \\
\hline 17 & Davis & $0.77 \pm 0.10$ & $0.64-0.97$ \\
\hline 18 & Brooks & $0.77 \pm 0.15$ & $0.50-1.10$ \\
\hline 19 & Stuart & $0.77 \pm 0.18$ & $0.54-1.01$ \\
\hline 20 & Owens & $0.76 \pm 0.10$ & $0.53-0.88$ \\
\hline 21 & Maramec & $0.75 \pm 0.13$ & $0.64-1.04$ \\
\hline 22 & Delmas & $0.74 \pm 0.11$ & $0.59-0.90$ \\
\hline 23 & Cape Fear & $0.72 \pm 0.14$ & $0.47-0.87$ \\
\hline 24 & Mobile & $0.70 \pm 0.14$ & $0.54-0.90$ \\
\hline 25 & Frotscher & $0.69 \pm 0.15$ & $0.47-0.91$ \\
\hline 26 & Melrose & $0.69 \pm 0.17$ & $0.46-0.96$ \\
\hline 27 & Shawnee & $0.69 \pm 0.08$ & $0.56-0.81$ \\
\hline 28 & Farley & $0.68 \pm 0.18$ & $0.49-1.10$ \\
\hline 29 & Forkert & $0.68 \pm 0.06$ & $0.62-0.77$ \\
\hline \multicolumn{4}{|c|}{ Thin or "papershell" $(<0.68 \mathrm{~mm})$} \\
\hline 30 & Shoshoni & $0.66 \pm 0.17$ & $0.49-0.97$ \\
\hline 31 & Mohawk & $0.65 \pm 0.13$ & $0.38-0.86$ \\
\hline 32 & Chickasaw & $0.64 \pm 0.12$ & $0.37-0.79$ \\
\hline 33 & Moore & $0.63 \pm 0.14$ & $0.47-0.90$ \\
\hline 34 & Sumner & $0.62 \pm 0.08$ & $0.49-0.71$ \\
\hline 35 & Pawnee & $0.62 \pm 0.09$ & $0.46-0.82$ \\
\hline 36 & Zink & $0.62 \pm 0.11$ & $0.51-0.87$ \\
\hline 37 & Curtis & $0.62 \pm 0.10$ & $0.40-0.73$ \\
\hline 38 & Teche & $0.61 \pm 0.11$ & $0.40-0.74$ \\
\hline 39 & Mahan & $0.61 \pm 0.10$ & $0.49-0.73$ \\
\hline 40 & Moreland & $0.60 \pm 0.16$ & $0.32-0.77$ \\
\hline 41 & Woodard & $0.58 \pm 0.19$ & $0.38-1.00$ \\
\hline 42 & Wichita & $0.57 \pm 0.11$ & $0.29-0.72$ \\
\hline 43 & Schley & $0.54 \pm 0.11$ & $0.37-0.77$ \\
\hline 44 & Barton & $0.43 \pm 0.07$ & $0.33-0.56$ \\
\hline 45 & Cheyenne & $0.42 \pm 0.06$ & $0.35-0.51$ \\
\hline 46 & Hastings & $0.39 \pm 0.03$ & $0.35-0.46$ \\
\hline
\end{tabular}

Mean shell thickness at two locations per nut on 10 nuts of each cultivar $\pm \mathrm{SD}$. Measurements were made near the plane of the middle septum, $25 \%$ of the distance from the base to the apex. Shell thickness classification was determined by dividing the range from thickest to thinnest into three equal divisions of $0.29 \mathrm{~mm}$ each.

\section{Literature Cited}

Forbus, W.R., Jr., S.D. Senter, and R.L. Wilson. 1983. Physical properties of pecan relating to shelling efficiency. J. Food Sci. 48:800-803, 816.

Johnson, R.A. and D.W. Wicheren. 1982. Applied multivariate statistical analysis. Prentice Hall, Englewood Cliffs, N.J.

Kays, S.J. and J.A. Payne. 1982. Analysis of physical and chemical parameters of the shells of pecan genotypes in reference to the production of phenolic plastics and resins. HortScience 17:978-980

Reid, J.T. and E.K. Heaton. 1977. The effect of mechanical cleaning and harvesting operations on shell-breaking and nutmeat quality of pecans. Trans. Amer. Soc. Agr. Eng. 20:623625 . 